\title{
Intrapulmonary solitary fibrous tumor with adenofibromatous pattern with features of pleomorphic high grade sarcoma-a case report and an overview of the differential diagnosis
}

\author{
Robbert J. H. van Leeuwen ${ }^{1 \#}$, Stefanie Brunner ${ }^{1 \#}$, Jan Pojda ${ }^{2}$, Joachim Diebold ${ }^{2}$, Peter Kestenholz ${ }^{3}$, \\ Fabrizio Minervini ${ }^{3} \wedge$ \\ ${ }^{1}$ Department of Surgery, Luzerner Kantonsspital, Lucerne, Switzerland; ${ }^{2}$ Department of Pathology, Luzerner Kantonsspital, Lucerne, Switzerland; \\ ${ }^{3}$ Department of Thoracic Surgery, Luzerner Kantonsspital, Lucerne, Switzerland \\ \#These authors contributed equally to this work.
}

Correspondence to: Fabrizio Minervini, MD, PhD. Department of Thoracic Surgery, Luzerner Kantonsspital, Lucerne, Switzerland. Email: fabriziominervini@hotmail.com.

Submitted Apr 22, 2020. Accepted for publication Aug 19, 2020.

doi: 10.21037/qims-20-598

View this article at: http://dx.doi.org/10.21037/qims-20-598

\section{Introduction}

Solitary fibrous tumors (SFTs) are ubiquitous mesenchymal neoplasms with a mostly indolent clinical course. They are most often found in the pleura, even if extrapleural SFTs can arise at almost any location. They are usually asymptomatic lesions and are most commonly diagnosed in older patients. As opposed to pleural lesions, intrapulmonary SFTs without direct connection to the pleura have been found to be rare lesions. In this paper, we report a case of an intrapulmonary SFT with an adenofibromatous pattern and areas with high grade histology resembling pleomorphic sarcoma.

\section{Case presentation}

A 71-year-old Caucasian female patient presented herself to the general practitioner with a strong cough, tiredness and fever since 1 week. In patient's history only an arterial hypertension was documented. She is a former smoker (5 pack/years, more than 40 years ago), without allergies. The family history was negative for lung cancer. The general practitioner performed a chest $\mathrm{X}$-ray which showed a pneumonia, but an additional sharp bordered lesion of
$5.5 \times 6.5 \mathrm{~cm}$ was seen in the right middle lobe (Figure 1 ). The patient recovered from the pneumonia after an antibiotic treatment with clindamycin for 1 week. After recovery, a computed tomography (CT) was conducted and showed a $6.9 \times 5.6 \times 5.7 \mathrm{~cm}$ lesion (Figure 2). A bronchoscopy and a positron-emission-tomography-CT (PET-CT) were conducted, where in the bronchoscopy no malignant cells could be detected and in the PET-CT, no activity of the tumor was shown, as well no lymphatic or hematogenous metastases. In the interdisciplinary tumor conference, we decided for a right middle lobe resection and mediastinal lymphadenectomy. Before surgery, a spirometry was performed which showed a normal lung function [forced expiratory volume in 1 second $\left(\mathrm{FEV}_{1}\right)$ of $113 \%$ and a diffusing capacity of carbon monoxide (DLCO) of 114\%].

A triportal VATS lobectomy along with mediastinal radical lymphadenectomy was performed. The patient was layered in left lateral position and three portals were placed (midclavicular $3 \mathrm{~cm}$ surgery sleeve and two $11.5 \mathrm{~mm}$ trocars). A $30^{\circ}$ optic was introduced (see Figure 3) and showed the tumor in the right middle lobe without suspicion of infiltrative growth in the upper or

^ ORCID: Robbert J. H. van Leeuwen, 0000-0003-0505-8933; Fabrizio Minervini, 0000-0003-3595-7307. 

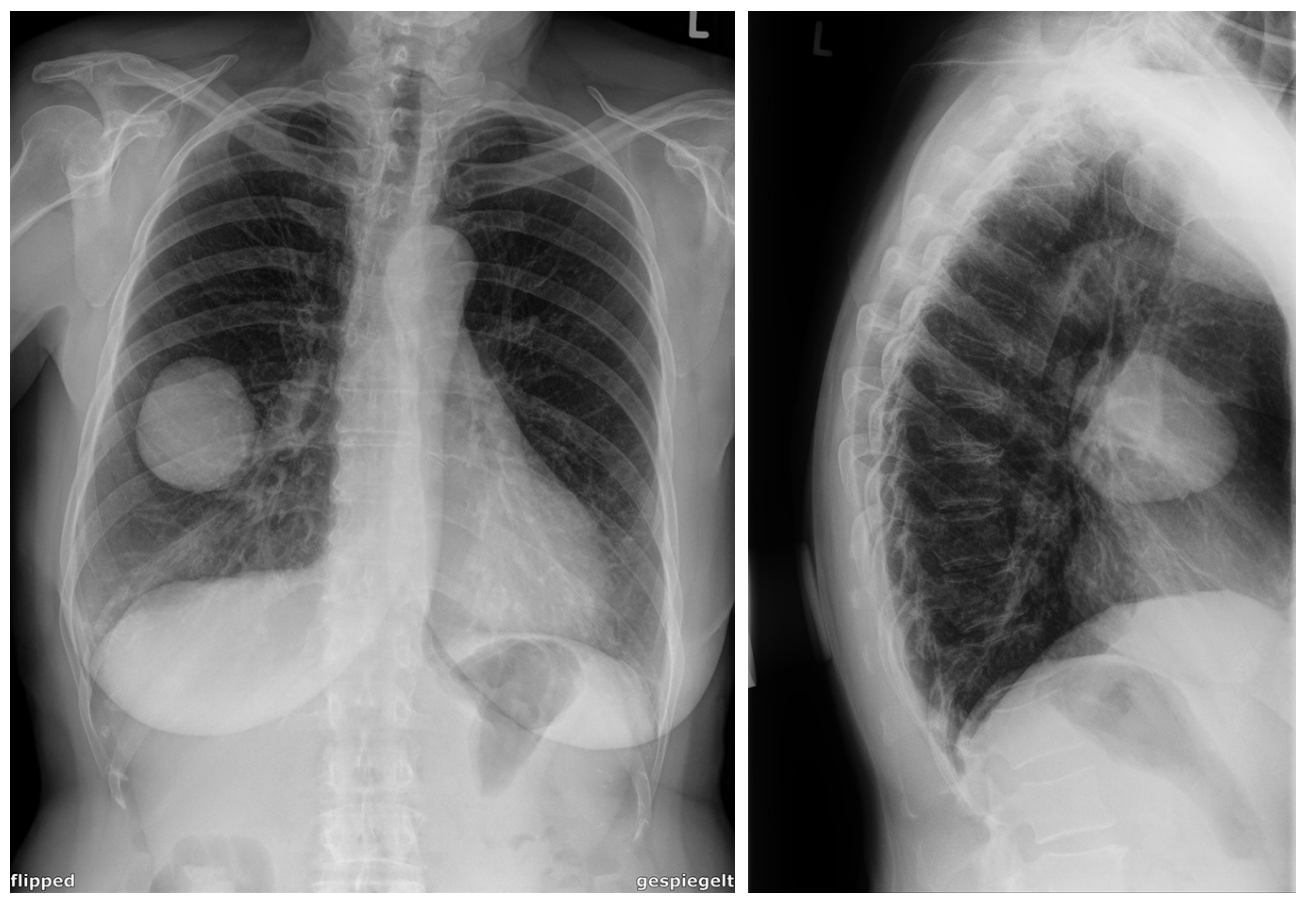

Figure 1 Chest X-ray at first presentation, end of December 2018.

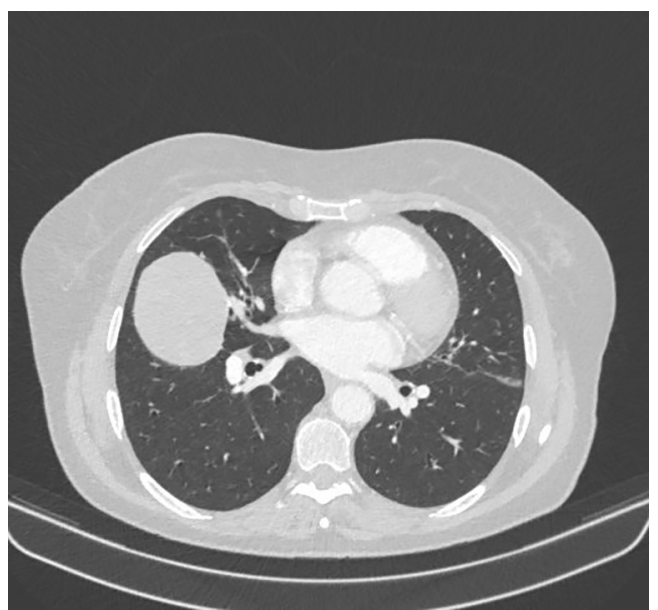

Figure 2 Follow up computed tomography (CT) scan with the lesion measured $6.9 \times 5.6 \times 5.7 \mathrm{~cm}$.

lower right lobe. Also, no pleural metastases were observed. The resection could be conducted without complications, and afterwards a lymphadenectomy (stations $2 \mathrm{R}, 4 \mathrm{R}, 7,8 \mathrm{R}$, $9 \mathrm{R}, 11 \mathrm{R}$ and $12 \mathrm{R}$ ) was performed. On the $4^{\text {th }}$ post-operative day (POD) the chest tube was removed and a chest X-ray did not show any signs of a pneumothorax. Five days after surgery, the patient was discharged without complications. In our interdisciplinary tumor board, no adjuvant therapy

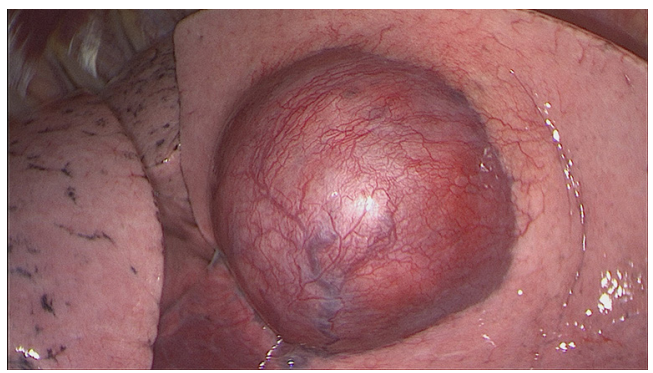

Figure 3 Intraoperative pictures of the lesion in the right middle lobe.

was advised. After a 1-year follow-up there has been no signs of local or distant recurrence.

\section{Histologic results}

The $14 \times 5.6 \times 5.5 \mathrm{~cm}$ lobectomy-specimen was submitted for histopathological examination and revealed the presence of a well circumscribed mass of $7.2 \mathrm{~cm}$, with a homogenous grey-yellowish cut surface without necrosis or hemorrhage. Despite having a peripheral location, the lesion had no direct relation to the overlying pleura and was from all sides surrounded by a rim of pleural parenchyma.

The microscopic examination showed a mesenchymal lesion containing glandular spaces lined by flat/cuboidal 


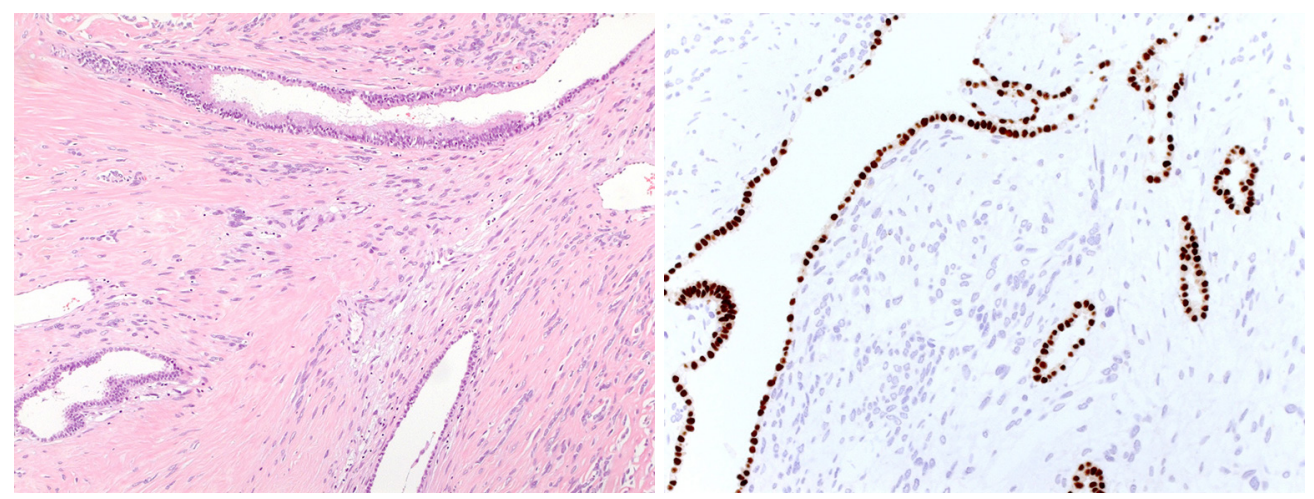

Figure 4 Glandular spaces with an eosinophilic colloid-like material with strong nuclear positivity for TTF1. The magnification is $5 \times$ (left) and $20 \times$ (right). Both are stained with conventional HE staining.

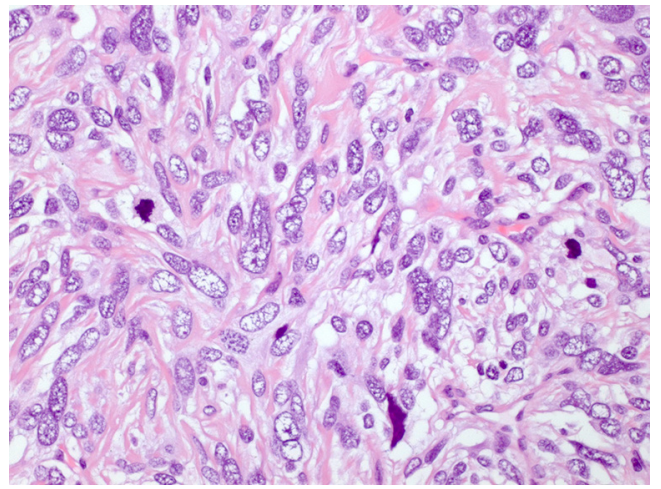

Figure 5 High mitotic rate (100× magnification with HE staining).

to columnar ciliated epithelial cells of the respiratory type surrounded by stroma consisting of spindle cells with a patternless architecture within a fibrotic matrix. The glandular spaces were mostly present at the periphery of the tumor and ranged from a few millimeters to less than $0.1 \mathrm{~mm}$ in size, some of the smallest ones being filled with an eosinophilic colloid-like material (Figure 4). The stromal cells mostly had a bland spindly appearance with tapered ends, small nuclei and sparse mitotic figures. There were, however, focal areas with increased cellularity and significant nuclear pleomorphism with the presence of bizarre and multinucleated cells. These areas resembled a pleomorphic high grade sarcoma and showed increased mitotic activity, the highest mitotic count being 8 mitoses per 10 high power fields (HPFs) (Figure 5). Paucicellular areas with sclerosis were also seen and some intratumoral blood vessels were surrounded by somewhat more sclerotic stroma. There was no evidence of the tumor at the margin.

The immunohistochemical work-up showed the stromal cells to be strongly and diffusely positive for the markers CD34, STAT6 (nuclear positivity) and bcl2, with focal areas also being positive for CD99 and estrogen receptor. In addition, the stromal cells in the atypical areas showed Vstrong and diffuse nuclear positivity for $\mathrm{p} 53$, however with a retained expression of CD34 (Figure 6). There was no positivity for actin, desmin or EMA and the ki-67 proliferative activity was $20-25 \%$. The epithelial lining of the glandular spaces showed strong nuclear positivity for TTF1 (Figure 4).

The diagnosis rendered was intrapulmonary SFT with adenofibromatous pattern and focal high grade histology with features of pleomorphic high grade sarcoma. Lymphadenectomy (inferior mediastinal lymph nodes: subcarinal, paraesophageal and pulmonary ligament lymph nodes stations 7,8,9; upper mediastinal lymph nodes; upper and lower paratracheal stations 2,4 as well as some lobar nodes of station 12) yielded 24 benign lymph nodes without evidence of metastasis.

\section{Discussion}

SFTs were first described in 1931 by Klemperer and Coleman who divided pleural tumors into diffuse and localized proposing submesothelial cells as the origin of the localized form $(1,2)$. SFTs most commonly arise in the pleura are thus most often encountered in the thoracic cavity. Extrapleural SFTs, however, can occur at nearly all anatomic locations including retroperitoneum, deep soft tissues of the extremities, head and neck as well as the abdominal cavity $(3,4)$. SFTs have an equal gender distribution and can occur at any age, however they are most commonly diagnosed in the $5^{\text {th }}$ to $6^{\text {th }}$ decade of life (5). 

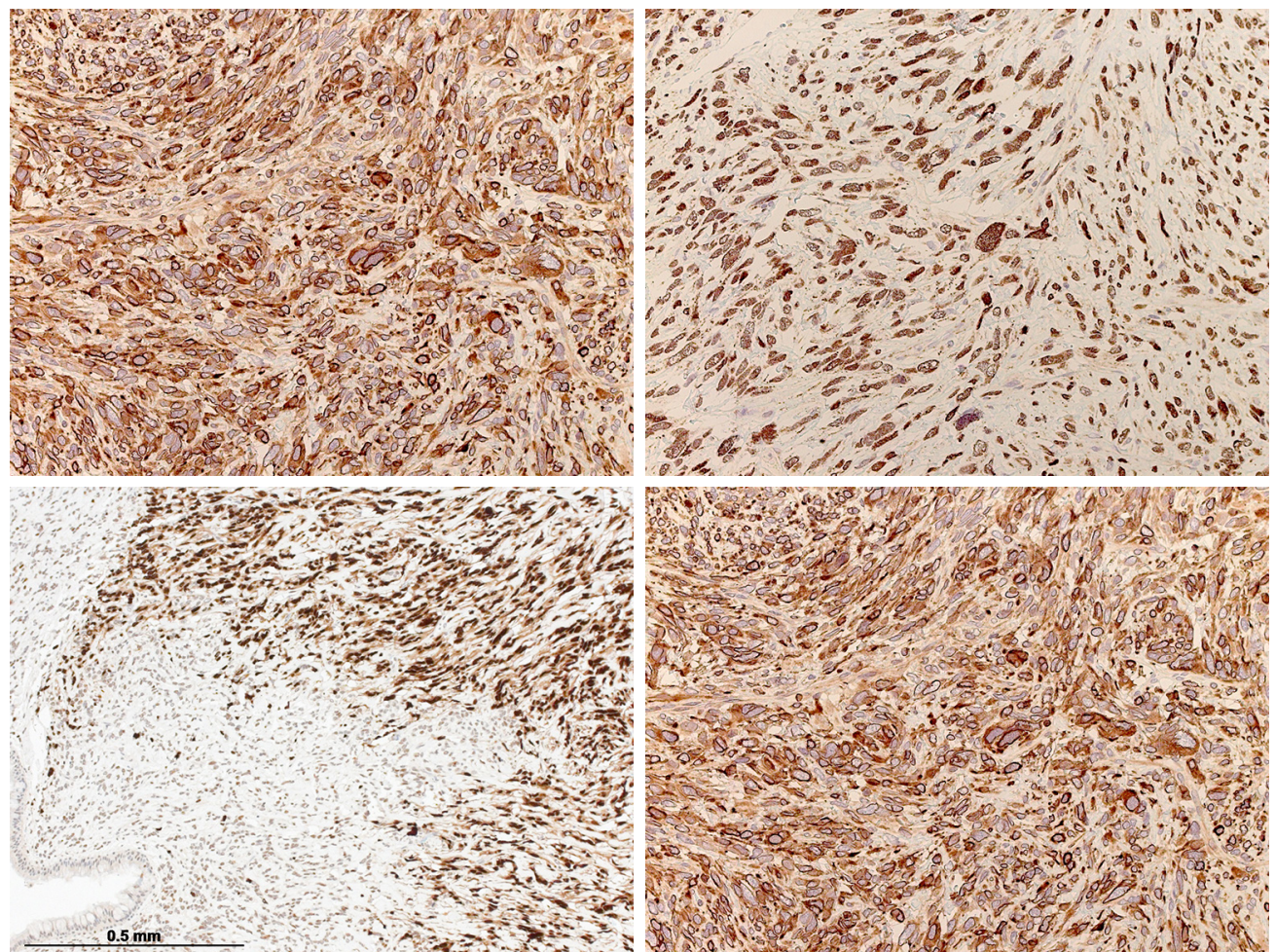

Figure 6 High expression of CD34, STAT6, p53 and bcl2 (clockwise, start upper left). The stainings are described under the figure with an antibody-clone-staining. The magnification is $20 x$.

There appear to be no known environmental risk factors increasing the risk of their occurrence (5).

Most (50-80\%) thoracic SFTs are asymptomatic and are detected as incidental findings on imaging (5). On CT they present as well circumscribed masses, hypodense or hyperdense compared to muscle tissue depending on collagen content, with increased density in collagenrich lesions. At MRI the lesions appear isointense on T1weighted images and variable on T2-weighted images with low-signal-intensity foci on both $\mathrm{T} 1$ and $\mathrm{T} 2$ weighted images and a chocolate chip cookie appearance. Enhancement is vigorous on both CT and MRI. Malignant SFTs can also have a well circumscribed border, just like benign lesions. The radiological differential diagnosis of intrapulmonary SFTs includes carcinoids, thymic neoplasias, teratomas and hamartomas (6). These radiological appearances are not very specific, so the diagnosis of intrapulmonary SFT is difficult to obtain.

Histologically, SFTs consist of bland fibroblast-like cells with spindly to ovoid nuclei as well as collagen bands in a random arrangement, commonly referred to as patternless distribution. Cellular areas with less stroma are seen alongside paucicellular zones and are richer in collagen. Some cases additionally display a prominent network of capillaries with the presence of staghorn blood vessels, known as hemangiopericytic growth pattern. Mitotic rates are usually low (less than 4 mitoses per $10 \mathrm{HPFs}$ ) and there is little to no cellular pleomorphism. Some tumors display increased mitotic activity and cellular atypia, features that have been associated with potential malignant behavior $(5,7)$. Tumors with a high-grade sarcomatous or anaplastic component as in our case have been referred to as dedifferentiated SFTs $(8,9)$. In rare cases fat production (socalled fat forming SFT), myxoid change and multinucleated giant cells can be seen (5).

The most valuable immunohistochemical markers in the diagnosis of SFTs are STAT6, CD34, bcl2 and CD99, with the first three being diffusely and strongly positive in our case (10). In addition, strong expression of p53 has been shown in malignant lesions, in some cases accompanied by loss of CD34 expression (11). On a molecular level, SFTs have been shown to be pathogenetically linked to a gene fusion involving NAB2 and STAT6 as a result of a paracentric inversion on chromosome $12 \mathrm{q} 13$ (12-14). The 
discovery of the NAB2-STAT6 has led to the inclusion of lesions hitherto known as hemangiopericytomas into the SFT tumor category (5).

While most SFTs behave in a benign or indolent fashion, some tumors (12-22\%) follow a malignant clinical course with metastasis and recurrence (15). Parameters which have found to be associated with malignant behavior include large tumor size (especially $>10 \mathrm{~cm}$ ), high mitotic rate ( $>4$ mitoses per 10 high-power fields), high cellularity, nuclear pleomorphism and the presence of necrosis and/ or hemorrhage (16). Nevertheless, the clinical course can be unpredictable in many cases with some benign tumors with R0 resection status also recurring (17). Extrapleural SFTs are thought to behave in a somewhat more malignant fashion than pleural forms (14). With regard to cases with a sarcomatous component, a series by Collini et al. showed seven of ten patients died of the disease with median overall survival of 73 months (18). In a series of cases by Mosquera and Fletcher three out of seven patients with dedifferentiated SFT died of the disease (9).

Radical surgery remains the mainstay treatment of SFTs with the resection margin status having a significant impact on the clinical outcome (17). Advanced SFTs carry a poor prognosis with anthracycline and/or ifosfamide-based chemotherapy showing little efficacy in most cases $(19,20)$. Recently novel agents such as temozolomide-bevacizumab, sunitinib, sorafenib and pazopanib have shown more promising results in the treatment of advanced cases (20).

As opposed to pleural lesions, intrapulmonary SFTs without involvement of the pleura appear to be rare with the first description of three unequivocal intrapulmonary tumors in 1988 by Yousem and Flynn (21). Interestingly their report mentions common entrapment of alveolar and bronchial epithelium in the lesions. In a series of 24 intrapulmonary SFTs, Rao et al. found intrapulmonary SFTs to be well circumscribed unencapsulated lesions ranging in size from 2.3 to $22 \mathrm{~cm}$ with a mostly peripheral location, yet with no relation to the visceral pleura. Twenty-one of the cases reported showed conventional low grade SFT histology with a low mitotic rate. One tumor showed intermediate histological features and two tumors displayed high grade histology resembling high grade pleomorphic sarcoma. Five of the tumors had an adenofibromatous pattern with epithelial lined glandular spaces at the periphery, representing entrapped pulmonary air spaces. However, in Rao's series, all of the five SFTs with adenofibromatous pattern displayed low grade histology, unlike in our case. The two cases with high grade histology in Rao's series died 4 and 7 years respectively after diagnosis. All patients with low grade histology had a favorable outcome (22).

With regard to pulmonary adenofibromas (PAFs), the distinction between these lesions and intrapulmonary SFTs with an adenofibromatous pattern and pulmonary hamartomas $(\mathrm{PH})$ in the literature has not always been clear (23-25). PAFs are generally defined as benign biphasic soft tissue tumors composed of epithelial and stromal elements (26). The glandular spaces within them have a papillary club-like appearance and are scattered throughout the lesion, rather than being concentrated at the periphery. Accordingly, the term biphasic lesion appears to be more pertinent to an adenofibroma, whereas the glandular structures within adenofibromatous SFTs are best described as entrapment (22). The two cases described by Suster in 1993 which were reminiscent of adenofibromas of the genital tract and had the appearance of coin lesions were hypothesized by the authors to be immature forms of PH (25). Negativity for CD34, STAT6 and bcl2 supports the diagnosis of an adenofibroma. It seems that caution is advised when diagnosing PAF, lesions which seem to be benign in character in analogy to $\mathrm{PH}$, and a SFT with adenofibromatous pattern, being a lesion with potential for progression, should in our opinion be excluded in every case.

$\mathrm{PH}$, being mixed lesions with mesenchymal and epithelial components, are certainly an important differential diagnosis when confronted with a biphasic lesion. They are benign tumors, most commonly seen in men in the $6^{\text {th }}$ decade of life, consisting of mesenchymal elements such as cartilage, fat, myxomatous tissue and smooth muscle with entrapped epithelial-lined slit-like spaces. The combination of different mesenchymal components makes this lesion easy to differentiate from an SFT. Most PHs present as so-called coin lesions on imaging, some larger however can measure several centimeters in size. The radiological diagnosis of PHs is also facilitated by the presence of fat and so-called popcorn-calcifications (27-29).

Another important entity to consider in the differential diagnosis is synovial sarcoma which can display a similar growth pattern to SFT and can furthermore exhibit immunohistochemical positivity for bcl2 and CD99. Leiomyomas and leiomyosarcomas are additional diagnoses to be taken into consideration (22). Immunohistochemical expression of the marker STAT6 which is highly specific and sensitive for SFTs is of great value in cases, in which morphology is equivocal (30). 


\section{Conclusions}

Intrapulmonary SFTs occur much more rarely than their pleural counterparts and not many cases have been reported. They share the characteristics of pleural SFTs and can also possess high grade histologic features as seen in our case.

\section{Acknowledgments}

Funding: None.

\section{Footnote}

Conflicts of Interest: All authors have completed the ICMJE uniform disclosure form (available at http://dx.doi. org/10.21037/qims-20-598). The authors have no conflicts of interest to declare.

Ethical Statement: The authors are accountable for all aspects of the work in ensuring that questions related to the accuracy or integrity of any part of the work are appropriately investigated and resolved. Written informed consent was obtained from the patient for publication of this case report and any accompanying images.

Open Access Statement: This is an Open Access article distributed in accordance with the Creative Commons Attribution-NonCommercial-NoDerivs 4.0 International License (CC BY-NC-ND 4.0), which permits the noncommercial replication and distribution of the article with the strict proviso that no changes or edits are made and the original work is properly cited (including links to both the formal publication through the relevant DOI and the license). See: https://creativecommons.org/licenses/by-nc-nd/4.0/.

\section{References}

1. Klemperer P, Coleman BR. Primary neoplasms of the pleura. A report of five cases. Am J Ind Med 1992;22:1-31.

2. Harrison-Phipps KM, Nichols FC, Schleck CD, Deschamps C, Cassivi SD, Schipper PH, Allen MS, Wigle DA, Pairolero PC. Solitary fibrous tumors of the pleura: results of surgical treatment and long-term prognosis. J Thorac Cardiovasc Surg 2009;138:19-25.

3. Han Y, Fu XL, Song YX, Wang JC, Ren T. Clinicopathologic features and prognostic factors of extrapleural solitary fibrous tumor. Int J Clin Exp Pathol
2016;9:9259-67.

4. Wignall OJ, Moskovic EC, Thway K, Thomas JM. Solitary fibrous tumors of the soft tissues: review of the imaging and clinical features with histopathologic correlation. AJR Am J Roentgenol 2010;195:W55-62.

5. Davanzo B, Emerson RE, Lisy M, Koniaris LG, Kays JK. Solitary fibrous tumor. Transl Gastroenterol Hepatol 2018;3:94.

6. Ginat DT, Bokhari A, Bhatt S, Dogra V. Imaging features of solitary fibrous tumors. AJR Am J Roentgenol 2011;196:487-95.

7. Suter M, Gebhard S, Boumghar M, Peloponisios N, Genton CY. Localized fibrous tumours of the pleura: 15 new cases and review of the literature. Eur J Cardiothorac Surg 1998;14:453-9.

8. Olson NJ, Linos K. Dedifferentiated solitary fibrous tumor: a concise review. Arch Pathol Lab Med 2018;142:761-6.

9. Mosquera JM, Fletcher CDM. Expanding the spectrum of malignant progression in solitary fibrous tumors: a study of 8 cases with a discrete anaplastic component--is this dedifferentiated SFT? Am J Surg Pathol 2009;33:1314-21.

10. Geramizadeh B, Marzban M, Churg A. Role of immunohistochemistry in the diagnosis of solitary fibrous tumor, a review. Iran J Pathol 2016;11:195-203.

11. Yokoi T, Tsuzuki T, Yatabe Y, Suzuki M, Kurumaya H, Koshikawa T, Kuhara H, Kuroda M, Nakamura N, Nakatani Y, Kakudo K. Solitary fibrous tumour: significance of $\mathrm{p} 53$ and $\mathrm{CD} 34$ immunoreactivity in its malignant transformation. Histopathology 1998 May;32:423-32.

12. Mohajeri A, Tayebwa J, Collin A, Nilsson J, Magnusson L, von Steyern FV, Brosjö O, Domanski HA, Larsson O, Sciot R, Debiec-Rychter M, Hornick JL, Mandahl N, Nord KH, Mertens F. Comprehensive genetic analysis identifies a pathognomonic NAB2/STAT6 fusion gene, nonrandom secondary genomic imbalances, and a characteristic gene expression profile in solitary fibrous tumor. Genes Chromosomes Cancer 2013;52:873-86.

13. Chmielecki J, Crago AM, Rosenberg M, O'Connor R, Walker SR, Ambrogio L, Auclair D, McKenna A, Heinrich MC, Frank DA, Meyerson M. Whole-exome sequencing identifies a recurrent NAB2-STAT6 fusion in solitary fibrous tumors. Nat Genet 2013;45:131-2.

14. Ronchi A, Cozzolino I, Zito Marino F, Accardo M, Montella M, Panarese I, Roccuzzo G, Toni G, Franco R, De Chiara A. Extrapleural solitary fibrous tumor: a distinct entity from pleural solitary fibrous tumor. An update on 
clinical, molecular and diagnostic features. Ann Diagn Pathol 2018;34:142-50.

15. Robinson LA. Solitary fibrous tumor of the pleura. Cancer Control 2006;13:264-9.

16. Gold JS, Antonescu CR, Hajdu C, Ferrone CR, Hussain M, Lewis JJ, Brennan MF, Coit DG. Clinicopathologic correlates of solitary fibrous tumors. Cancer 2002;94:1057-68.

17. Ghanim B, Hess S, Bertoglio P, Celik A, Bas A, Oberndorfer F, Melfi F, Mussi A, Klepetko W, Pirker C, Berger W, Harmati I, Farkas A, Jan Ankersmit H, Dome B, Fillinger J, Aigner C, Hegedus B, Renyi-Vamos F, Lang G. Intrathoracic solitary fibrous tumor - an international multicenter study on clinical outcome and novel circulating biomarkers. Sci Rep 2017;7:12557.

18. Collini P, Negri T, Barisella M, Palassini E, Tarantino E, Pastorino U, Gronchi A, Stacchiotti S, Pilotti S. Highgrade sarcomatous overgrowth in solitary fibrous tumors: a clinicopathologic study of 10 cases. Am J Surg Pathol 2012;36:1202-15.

19. Levard A, Derbel O, Méeus P, Ranchère D, RayCoquard I, Blay JY, Cassier PA. Outcome of patients with advanced solitary fibrous tumors: the Centre Leon Berard experience. BMC Cancer 2013;13:109.

20. Park MS, Ravi V, Conley A, Patel SR, Trent JC, Lev DC, Lazar AJ, Wang WL, Benjamin RS, Araujo DM. The role of chemotherapy in advanced solitary fibrous tumors: a retrospective analysis. Clin Sarcoma Res 2013;3:7.

21. Yousem SA, Flynn SD. Intrapulmonary localized fibrous tumor. Intraparenchymal so-called localized fibrous mesothelioma. Am J Clin Pathol 1988;89:365-9.

22. Rao N, Colby TV, Falconieri G, Cohen H, Moran CA, Suster S. Intrapulmonary solitary fibrous tumors:

Cite this article as: van Leeuwen RJH, Brunner S, Pojda J, Diebold J, Kestenholz P, Minervini F. Intrapulmonary solitary fibrous tumor with adenofibromatous pattern with features of pleomorphic high grade sarcoma-a case report and an overview of the differential diagnosis. Quant Imaging Med Surg 2021;11(1):472-478. doi: 10.21037/qims-20-598 clinicopathologic and immunohistochemical study of 24 cases. Am J Surg Pathol 2013;37:155-66.

23. Cavazza A, Rossi G, De Marco L, Putrino I, Pellegrino S, Piana S. Solitary fibrous pseudopapillary tumor of the lung: pulmonary fibroadenoma and adenofibroma revisited. Pathologica 2003;95:162-6.

24. Hao J, Zhang C, Cao Q, Zou J, Wang C. Pulmonary adenofibroma: report of a case with multiple masses. Ann Clin Lab Sci 2016;46:691-5.

25. Suster S, Moran CA. Pulmonary adenofibroma: report of two cases of an unusual type of hamartomatous lesion of the lung. Histopathology 1993;23:547-51.

26. Corzani R, Bellan C, Luzzi L, Ghisalberti M, Ligabue T, Meniconi F, Astaneh A, Servillo SP, De Leonibus L, Paladini P. A rare pulmonary adenofibroma mimicking a metastatic lesion. Clin Surg 2017;2:1691.

27. Travis WD, Brambilla E, Burke AP, Marx A, Nicholson AG. Introduction to the 2015 World Health Organization Classification of tumors of the lung, pleura, thymus, and heart. J Thorac Oncol 2015;10:1240-2.

28. Park KY, Kim SJ, Noh TW, Cho SH, Lee DY, Paik HC, Ryu YH. Diagnostic efficacy and characteristic feature of MRI in pulmonary hamartoma: comparison with CT, specimen MRI, and pathology. J Comput Assist Tomogr 2008;32:919-25.

29. Singh H, Khanna SK, Chandran V, Jetley RK. Pulmonary hamartoma. Med J Armed Forces India 1999;55:79-80.

30. Demicco EG, Harms PW, Patel RM, Smith SC, Ingram D, Torres K, Carskadon SL, Camelo-Piragua S, McHugh JB, Siddiqui J, Palanisamy N, Lucas DR, Lazar AJ, Wang WL. Extensive survey of STAT6 expression in a large series of mesenchymal tumors. Am J Clin Pathol 2015;143:672-82. 